\title{
Effect of Nitrogen on Deformation-Induced Martensitic Transformation in an Austenitic 301 Stainless Steels
}

\author{
Jong Bae Jeon ${ }^{1, *}$ and Young Won Chang ${ }^{2, *}$ \\ 1 Functional Components and Materials R\&D Group, Korea Institute of Industrial Technology, \\ Yangsan 50635, Korea \\ 2 Department of Materials Science and Engineering, POSTECH, Pohang 37673, Korea \\ * Correspondence: jbjeon@kitech.re.kr (J.B.J.); ywchang@postech.ac.kr (Y.W.C.); \\ Tel.: +82-55-367-9407 (J.B.J.); +82-10-4810-2133 (Y.W.C.)
}

Received: 15 October 2017; Accepted: 10 November 2017; Published: 13 November 2017

\begin{abstract}
The effect of nitrogen on deformation-induced martensitic transformation (DIMT) in metastable 301 austenitic stainless steel has been studied based on the inelastic deformation theory. DIMT is regarded here as continuous relaxation process of internal strain energy accumulated during inelastic deformation. Using the kinetics equation based on the inelastic deformation theory the relationship between the volume fraction of transformed martensite and inelastic strain for DIMT has been successfully verified with the parameter representing the stability of austenite. The addition of nitrogen is experimentally found to increase austenite stability and the critical inelastic strain below which any DIMT is not observed to occur and to decrease the saturation volume fraction of $\alpha^{\prime}$ martensite. On the other hand, DIMT has been analyzed with its effect on stress-strain curve shape and mechanical properties in relation to the addition of nitrogen. The characteristic transition from sigmoidal to parabolic curve shape in stress-strain response has disappeared with the addition of nitrogen.
\end{abstract}

Keywords: austenitic 301 stainless steels; deformation-induced phase transformation; kinetics; nitrogen

\section{Introduction}

Deformation induced martensitic transformation (DIMT) has recently generated great interest in steel and automobile industries due to its role on achieving high strength steels with high ductility, so called transformation-induced plasticity (TRIP) steels. DIMT is known to take place when austenite is deformed at temperatures below $\mathrm{M}_{\mathrm{d}}$, which could be well above the transformation start temperature of martensite, $\mathrm{M}_{\mathrm{s}}$. Generally, the $\mathrm{M}_{\mathrm{d}}$ temperature strongly depends on chemical compositions, strain rate, and loading temperature. DIMT in austenitic stainless steels has been observed to proceed either directly from $\gamma$-austenite to $\alpha^{\prime}$ martensite $\left(\gamma \rightarrow \alpha^{\prime}\right)$ [1,2] or via $\varepsilon$ martensite $\left(\gamma \rightarrow \varepsilon \rightarrow \alpha^{\prime}\right)$ depending on alloy composition and crystallographic orientation [2-5]. Generally, DIMT phenomenon has been analyzed in terms of either transformation kinetics or stress-strain response [4,6-17]. The transformation kinetics of DIMT prescribes the relation between the volume fraction of transformed martensite and plastic strain, while the change in deformation behavior due to DIMT has also been analyzed in relation to the variation of stress-strain curve and mechanical properties $[1,10,13,18]$.

In order to obtain both high strength and ductility in TRIP steels, mechanisms of the formation of retained austenite, transformation behavior of retained austenite and the deformation behavior related to transformation should be thoroughly investigated $[4,11,12]$. In terms of DIMT kinetics, the stability of the retained austenite should not be either too high or too low for achieving optimized 
combination of strength and elongation. It is thus important to control that DIMT occurs with proper kinetics in a given composition and temperature for the desirable strength and elongation. Therefore, several studies have been conducted on the influential factors affecting DIMT kinetics, such as initial microstructure [19], composition [4], crystallographic orientation [20], temperature [18], and loading types [16,21].

In this research, transformation behavior of austenite by plastic deformation, in other words, deformation induced martensitic transformation (DIMT) has been studied with nitrogen addition effect using 301 austenitic stainless steels. Nitrogen provides beneficial effects as an alloying element on the properties, such as superior combination of high yield strength and high elongation, high fatigue life and wear resistance, high resistance to localized corrosion in 300 grade stainless steels [22]. Numbers of researcher have carried on the extensive studied on the relationship between DIMT and chemical compositions, suggesting their own kinetics equations for describing DIMT [1-9]. Although considerable knowledge base is available for austenitic stainless steel in general, the understanding developed for 301 stainless steel system with nitrogen effect is still lack [1,23]. Investigations are therefore necessary for better understanding on the topic. In this research, the effect of nitrogen on DIMT was investigated in austenitic 301 stainless steel. The experimental data was explicated in terms of (i) stress-strain curve and (ii) volume fraction of transformed martensite-strain curve, and validated with kinetics equation recently developed by Shin et al. [10].

\section{Materials and Methods}

Using a vacuum induction melting under nitrogen partial pressure, three types of austenitic steels were fabricated by POSCO technical laboratory with the chemical compositions as given in Table 1. In order to investigate the effect of nitrogen on DIMT, nitrogen contents were varied by controlling nitrogen partial pressure while the other alloying contents are almost constant in the selected materials. $30 \mathrm{~kg}$-ingots were homogenized at $120{ }^{\circ} \mathrm{C}$ and then hot rolled into $3 \mathrm{~mm}$ thick plate at $1050{ }^{\circ} \mathrm{C}$. Pickled in a solution of $10 \% \mathrm{HCl}$, the plate was cold rolled into $1.15 \mathrm{~mm}$ thick sheet at room temperature. For measuring DIMT kinetics, subsized plate-type tensile specimens with thickness of $1.15 \mathrm{~mm}$, gauge width of $5 \mathrm{~mm}$ and gauge length of $15 \mathrm{~mm}$ were machined from cold rolled sheets, while tensile tests specimen were machine according to ASTM-E8. Sealed in quartz tube, the specimens were annealed at $1050{ }^{\circ} \mathrm{C}$ for $30 \mathrm{~min}$ to remove transformed phase probably formed due to machining and then quenched directly into water. Grain sizes were observed to be $40 \sim 50 \mu \mathrm{m}$ for all three types of specimens regardless of nitrogen content. X-ray diffraction tests of as received specimen $\mathrm{A}, \mathrm{B}$ and $\mathrm{C}$ were performed using $\mathrm{X}$-ray diffractometer (Rigaku, Tokyo, Japan) with copper-targeted gun in $40 \mathrm{KeV}$ and $200 \mathrm{~mA}$ power. As given in Figure 1, XRD patterns show that all three types of specimens only have austenitic phase. Tensile tests were performed at room temperature under the nominal strain rate of $1.0 \times 10^{-3} \mathrm{~s}^{-1}$ using an electro-mechanical testing machine (Instron, Norwood, MA, USA). The volume fractions of transformed martensite were measured thru a magnetic induction method by using a commercial Feritscope (Fischer, Windsor, CT, USA). To avoid the Villari effect (inverse magnetostrictive effect), Feritscope measurement was conducted with unloading at each strain level [24]. In order to observe the microstructure, the test pieces were polished and then etched using a mixed solution of distilled water, hydrochloric acid and nitric acid with a ratio of 4:3:3. The microstructures of transformed phase were then observed using a scanning electron microscopy (SEM) (JEOL, Tokyo, Japan).

Table 1. Chemical composition of austenitic 301 stainless steels measured by ICP-OES.

\begin{tabular}{cccccccc}
\hline Alloys & $\mathbf{C}$ & $\mathbf{C r}$ & $\mathbf{N i}$ & $\mathbf{M n}$ & $\mathbf{A l}$ & $\mathbf{C u}$ & $\mathbf{N}$ \\
\hline A & 0.041 & 17.37 & 6.93 & 1.00 & 0.509 & 0.233 & - \\
B & 0.038 & 17.38 & 7.00 & 1.00 & 0.492 & 0.227 & 0.144 \\
C & 0.040 & 17.08 & 6.98 & 0.971 & 0.460 & 0.220 & 0.296 \\
\hline
\end{tabular}



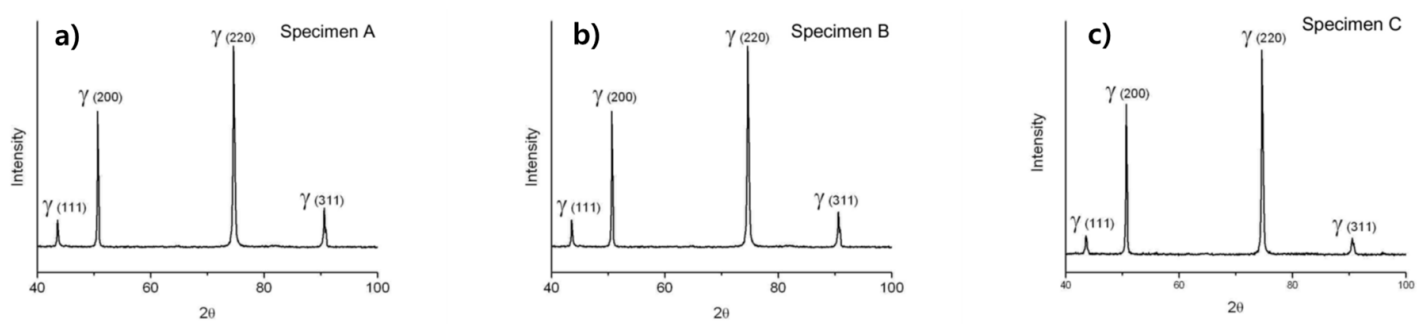

Figure 1. X-ray diffraction patterns of as-received specimens showing the presence of austenite in the initial samples.

\section{Results and Discussion}

\subsection{Effect of Nitrogen on Kinetics of DIMT}

The measured volume fractions of transformed martensite are plotted as a function of inelastic strain at room temperature in Figure 2 with the superimposed solid lines obtained by a least square fitting of the experimental data using the kinetics relation given by Equation (1). A kinetics equation has been proposed by Shin et al. was employed in this study [10]. In this kinetics equation, DIMT is viewed as continuous relaxation process of internal strain energy naturally developed during inelastic deformation [10,25]. In this equation, the internal strain energy naturally accumulated during inelastic deformation could provide the driving force deficiency for martensitic transformation above $\mathrm{M}_{\mathrm{s}}$ temperature.

$$
\frac{f}{f_{s}}=1-\exp \left[-\beta\left(\varepsilon-\epsilon_{0}\right)^{n}\right]
$$

The parameter $f$ and $f_{s}$ denote the volume fraction of transformed $\alpha^{\prime}$ martensite and its saturation value, respectively. The parameter $\beta$ represents austenite stability on a given composition and temperature. Increasing $\beta$ inversely indicates decreasing stability of retained austenite and the rate parameter $n$ denotes how quickly the nucleation sites are generated during deformation. It is well known that the nucleation site for DIMT is shear band intersection, and the formation of the shear band strongly depends on the loading type and crystallographic orientation in a given composition $[1,2,26]$. Therefore, the parameter $n$ can also be termed as a deformation mode parameter. $\varepsilon_{0}$ is critical inelastic strain for triggering DIMT. The details on the parameters are shown in elsewhere [10,13]. All parameter are dimensionless and can easily be obtained from experimental data with the Equation (1).

For obtaining sufficient data sets to verify the relationship between volume fraction of transformed martensite and inelastic strain, tensile specimens prepared from the same batch were strengthened to various strain levels. The volume fraction of transformed martensite shows its highest value in nitrogen-free specimen $A$ in entire strain range and drastically decreases in specimen $B$ and $C$ (0.144 wt. \% $\mathrm{N}$ and $0.296 \mathrm{wt}$. \% $\mathrm{N}$ respectively). However, the drastic change is not shown in between specimen $B$ and $C$ and this might come from that nitrogen effect on kinetics of DIMT is getting close to be saturated. The transformation rate of specimen $A$ is shown to be the fastest among the specimens and gradually becomes slow and saturated. The specimen B and C show slow transformation rate compared to specimen A until 30\% of inelastic strain. They are gradually getting faster until $70 \%$ of inelastic strain and seem to reach their saturation value afterwards.

A least square fitting of the experimental data using the Equation (1) exhibits the kinetics equations employed here is well matched with the experimental data. The transformation fitting parameters $\beta$, $n, f_{s}$ and $\varepsilon_{0}$ are listed in Table 2 . As given in Table 2 and Figure $2 b$, deformation mode parameter $n$ is observed to have a fixed value of 2.2, regardless of nitrogen contents. This result then suggests that despite of different nitrogen contents all three specimens have similar deformation characteristics for generation of DIMT nucleation site because the parameter $n$ is associated with the characteristics of inelastic deformation which generates defect sites for nucleation. The parameter $n$ was reported to be varied in austenitic stainless steels $[10,18]$. It is also reported in the study that using Fe-C-Mn steel 
$n$ value is changed from 1.4 to 1.0 at the transient temperature above which induced phase becomes deformation twin, and below which $\varepsilon$ martensite is induced phase [18].
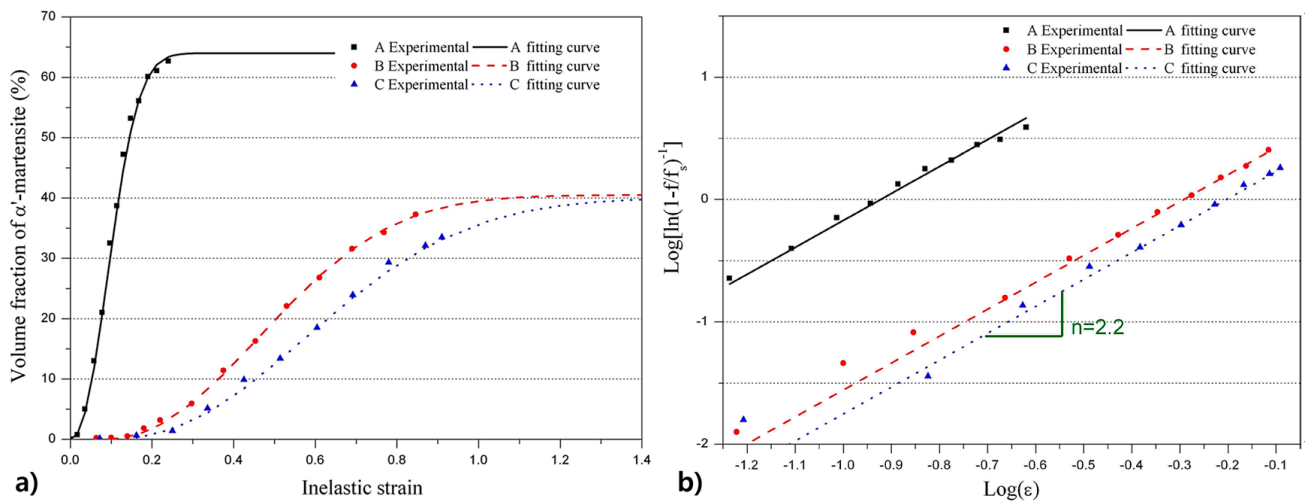

Figure 2. (a) Volume fraction of transformed $\alpha^{\prime}$-martensite as a function of inelastic strain; (b) a plot showing the deformation mode parameter $n=2.2$ regardless of nitrogen content.

Table 2. Transformation parameters and tensile properties.

\begin{tabular}{cccccccc}
\hline \multirow{2}{*}{ Alloys } & \multicolumn{3}{c}{ Transformation Parameters } & \multicolumn{3}{c}{ Tensile Properties } \\
\cline { 2 - 8 } & $f_{\boldsymbol{s}}$ & $\boldsymbol{\beta}$ & $\boldsymbol{n}$ & $\boldsymbol{\varepsilon}_{\mathbf{0}}$ & YS (MPa) & UTS (MPa) & UE (\%) \\
\hline A & 64 & 107 & 2.2 & 0.01 & 224 & 1067 & 38.4 \\
B & 40.5 & 4.4 & 2.2 & 0.08 & 412 & 863 & 50.1 \\
C & 40.0 & 2.8 & 2.2 & 0.1 & 373 & 825 & 53.3 \\
\hline
\end{tabular}

Due to stabilizing effect of nitrogen the saturation value of transformed $\alpha^{\prime}$ martensite $f_{\mathrm{S}}$ and the stability parameter $\beta$, which is inversely proportional to the austenite stability, are found to decrease with increasing nitrogen contents. The parameter $\beta$ was also reported to become lower as test temperature increases $[10,18,27]$. According to Equation (1), when the stability parameter $\beta$ is zero, the volume fraction of transformed $\alpha^{\prime}$ martensite should be zero as well. This parameter, therefore, can introduce convenient method for finding the $\mathrm{M}_{\mathrm{d}}$ temperature $[4,10,18]$, above which deformation of austenite phase does not form any martensite. Here the parameter $\beta$ is observed to drastically drop in the specimen B $(0.144 \mathrm{wt}$. \% N) and then be almost saturated in the specimen C $(0.296 \mathrm{wt} . \% \mathrm{~N})$. Although stability parameter didn't reach to zero within the nitrogen contents range in the present study, it can be implied that DIMT in room temperature will cease with more addition of nitrogen.

In order to understand the increase of austenite stability, i.e., less martensitic transformation with increasing nitrogen contents, let schematic free energy diagram be introduced in Figure 3. As shown in Figure 3, it is suggested that nitrogen-added austenite (specimen B and C) has lower free energy than nitrogen-free austenite (specimen A). It is known that the critical driving force for martensitic transformation $\Delta \mathrm{G}^{\gamma} \rightarrow \alpha^{\prime}$ is practically constant, approximately $1250 \mathrm{~J} \cdot \mathrm{mol}^{-1}$, independent of interstitial solute content [28]. Below $\mathrm{M}_{\mathrm{d} 2}$, both of nitrogen-free and nitrogen-added austenite have enough driving force more than the critical driving force $\Delta \mathrm{G}^{\gamma \rightarrow \alpha^{\prime}}$ and are thus able to be transformed into $\alpha^{\prime}$ martensite during deformation. However, the driving force for $\gamma \rightarrow \alpha^{\prime}$ transformation in nitrogen-added austenite is smaller than that of nitrogen-free austenite, and thereof the difference leads to the lower volume fraction of transformed $\alpha^{\prime}$ in the nitrogen-added austenite at a same strain level. In order to transform the nitrogen-added austenite into $\alpha^{\prime}$ martensite as same amount as nitrogen-free austenite, therefore, additional driving force in terms of plastic strain is required. This additional driving force is reported to be internal strain energy which is accumulated naturally owing to the dislocation pile-ups at impeding barriers such as phase boundaries during plastic deformation $[1,10,18,25]$. As the Figure 2 shows, for instance, in order to obtain about $30 \%$ of 
transformed martensite, specimen $B$ and $C$ need more than $\varepsilon=0.67$ and $\varepsilon=0.82$ of inelastic strain respectively, which are far higher values than $\varepsilon=0.08$ of specimen A. Moreover, in Table 2 the critical strain $\varepsilon_{0}$ for initiating DIMT is observed to be $\varepsilon_{0}=0.01$ in specimen $A$ and becomes higher in specimen $\mathrm{B}$ and $\mathrm{C}\left(\varepsilon_{0}=0.08\right.$ and 0.1 , respectively). This result then suggests that nitrogen-added austenite needs more driving force than nitrogen-free austenite in order to trigger DIMT.

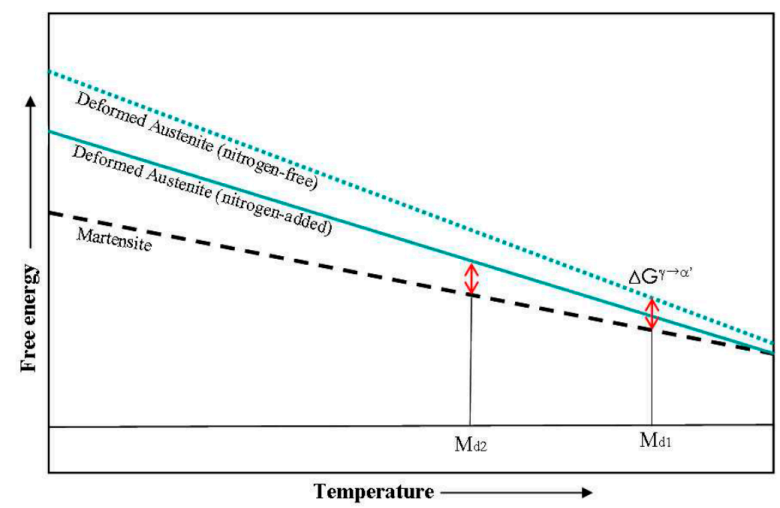

Figure 3. Schematic free energy diagram of deformation induced martensitic transformation (DIMT) at a certain strain level.

$\mathrm{M}_{\mathrm{d}}$ temperature is reported to be measured with empirical equations which express the effects of solute atoms on $M_{d}$ temperature [29]. Among these, the equation proposed by Sjöberg [29] took the independent effect of nitrogen into account and suggests that nitrogen is more effective alloying element to restrain DIMT than carbon.

$$
\mathrm{M}_{\mathrm{d}}=608-515[\% \mathrm{C}]-821[\% \mathrm{~N}]-7.8[\% \mathrm{Si}]-12[\% \mathrm{Mn}]-13[\% \mathrm{Cr}]-34[\% \mathrm{Ni}]-6.5[\% \mathrm{Mo}]
$$

Lee et al. [4] also reported in the study of austenitic 304 stainless steels that $\mathrm{M}_{\mathrm{d}}$ temperature measured indirectly as the temperature where austenite stability parameter $\beta=0$ decreased with increasing nitrogen contents. Figure 3 can schematically explain the reported decrease of $M_{d}$ temperature with increasing nitrogen contents. In Figure 3, nitrogen-added austenite doesn't have critical driving force at $\mathrm{M}_{\mathrm{d} 1}$ as much as nitrogen-free austenite, therefore needs to be cooled below the temperature $\mathrm{M}_{\mathrm{d} 2}$ in order to be transformed into martensite with the external plastic strain.

\subsection{Effect of Nitrogen on Tensile Properteis and Microstructure}

Table 2 and Figure 4 show engineering tensile properties and true stress-strain curves of austenitic 301 stainless steel with increasing nitrogen contents, respectively. As given in Table 2, yield strength (YS) increased with increasing nitrogen contents up to $0.144 \mathrm{wt}$. \% (specimen B) but decreased with further addition of nitrogen (Specimen C). This is contrary to the previous report in which yield stress monotonically increased with increasing nitrogen content up to $1.2 \mathrm{wt}$. \% [22]. On the other hand ultimate tensile strength (UTS) decreases but uniform elongation (UE) increases with increasing nitrogen contents in contrast to the previous report where DIMT doesn't take place [4]. These results are related to the stability of austenite in metastable austenite alloys. It is reported that as the stability of austenite increases, martensitic transformation took place uniformly throughout plastic deformation leading to the ductility improvement. When the austenite is too stable, however, DIMT process is now too slow to relax the internal strain energy effectively resulting in a sudden drop in strain hardening rate and a consequent failure at lower strain. This failure in early stage of plastic deformation also can be observed as resulted in specimen A when DIMT process occurs so fast that work-hardening rate increases rapidly. Therefore it is important to control the optimized stability of austenite in order to obtain high strength along with elongation in metastable austenitic alloys $[4,12]$. 
Figure 4 shows true stress-strain curves of all specimens. As seen in Figure 4, stress-strain curves of specimen A shows the transition from parabolic to sigmoidal curve shapes. This transition is reported to a characteristic feature of stress-strain response involving DIMT $[4,13,21,30]$. This shape change in flow behavior is reported to be due to the occurrence of DIMT and the transient strain at which the flow behavior changes from parabolic to sigmoidal shape is regarded as the onset of DIMT. Recently Lee et al. [4] reported in the study of Fe-18Cr-10Mn-N steels that the experimental stress-strain curves gradually deviate from the modified Ludwik relation after passing the transient strain at which the flow curve changes in shape from the parabolic to the sigmoidal and the deviation increased with further straining. Also, they reported that as nitrogen addition increases, the transient strain is shifted to a higher strain level and the deviation from the modified Ludwik relation became diminished. They said the transition was disappeared in higher nitrogen contents and DIMT is not observed to take place at the nitrogen level $(0.8 \mathrm{wt} . \% \mathrm{~N})$. In the present study however, specimen $\mathrm{B}$ and $\mathrm{C}$ in which DIMT take place doesn't show the transition behavior in their flow curve so that the shift of transient strain is not observed. It possibly comes from that the DIMT behavior occurs in slow and steady in entire strain regime in specimen B and C, so that the transition is not observed. These disappearance of the transition with increasing nitrogen in the stress-strain response represent that the formation of $\alpha^{\prime}$ martensite by DIMT, is suppressed with increasing nitrogen contents. As given Figure 2, DIMT kinetics results in the present study successfully verify the suppression of $\alpha^{\prime}$ martensite formation with increasing nitrogen contents. In TEM study of austenitic Fe- $18 \mathrm{Cr}-10 \mathrm{Mn}-\mathrm{N}$ steels, Lee et al. [4] defined the transient strain as the strain at which the $\alpha^{\prime}$ martensite begins to form. In the present study, $\alpha^{\prime}$ martensite was detected to start to form at critical strain $\varepsilon_{0}$ which is smaller value than transient strain of specimen A.
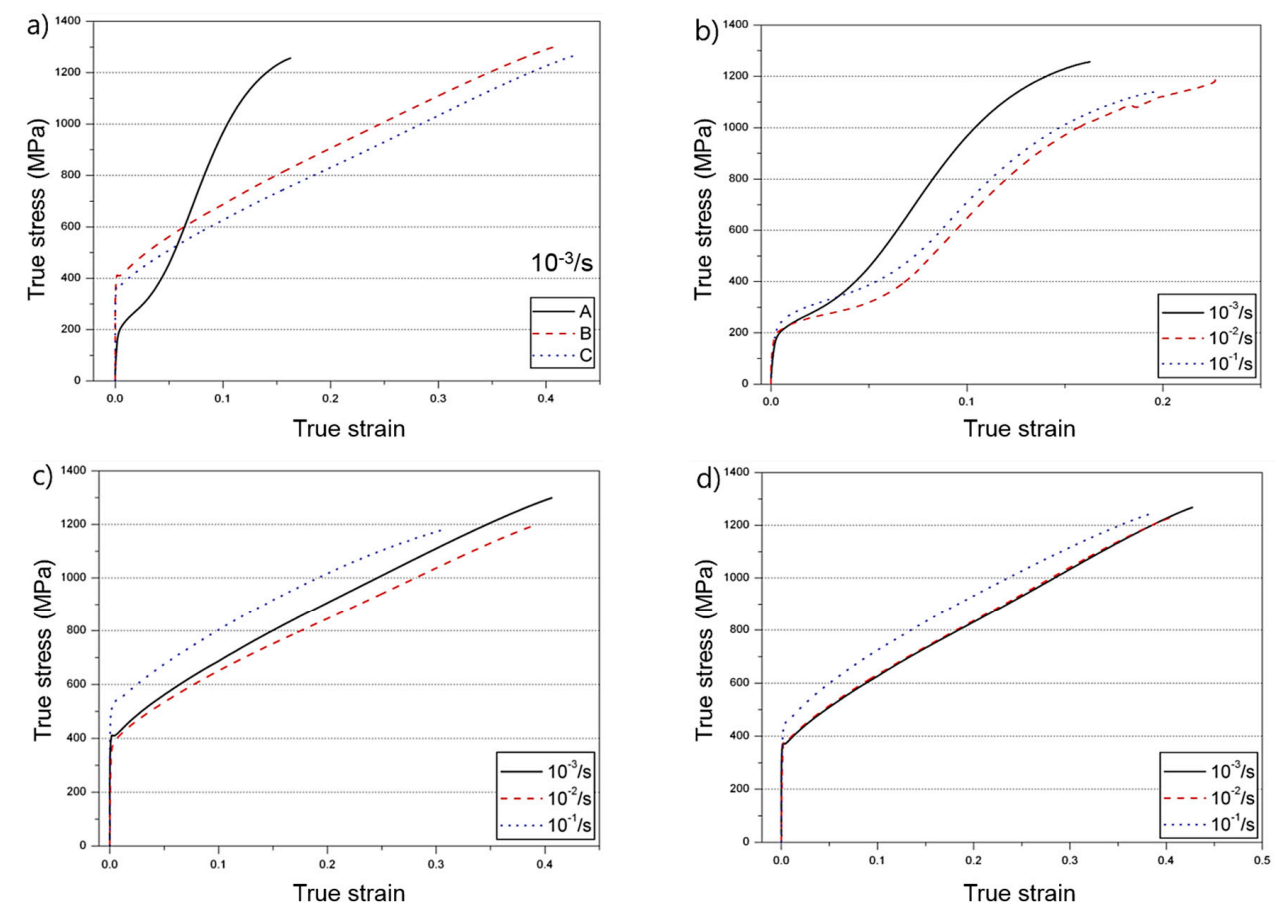

Figure 4. True stress-strain curves and speicimen A, B and C (a); (b-d) shows the effect of strain rate in specimen $\mathrm{A}, \mathrm{B}$ and $\mathrm{C}$ respectively.

The stability of austenite against DIMT is important to estimate the deformation character of austenitic steels. Figure $4 \mathrm{~b}-\mathrm{d}$ shows true strain-stress curves at three different strain rate in specimen $\mathrm{A}, \mathrm{B}$ and $\mathrm{C}$ respectively. When strain rate becomes higher from $0.001 \mathrm{~s}^{-1}$ to $0.1 \mathrm{~s}^{-1}$, specimen $\mathrm{A}$ shows higher elongation and lower flow stress, while other specimens exhibit opposite behavior. Generally strain rate sensitivity of materials in room temperature ranges from 0 to 0.03 so that flow 
stress increases and elongation decreases in higher strain rate condition. Specimen A however, shows negative strain rate sensitivity and this behavior is possibly related to the stability of austenite. Specimen A consists of unstable austenite phase so that the transformation rate is very fast even in the low strain regime as explained in the DIMT kinetics (Figure 2). The stability of austenite is reported to increase if deformation is conducted in higher temperature or higher strain rate $[1,10]$. In both conditions the temperature at which DIMT occurs is higher so that the stability can increase. The negative strain rate sensitivity can be explain in such a way that high strain rate makes the austenite more stable ans thus DIMT occurs in more slow and steady way [16].

Figure 5 exhibits decreasing volume of transformed martensite with increasing nitrogen contents. Regardless of the nitrogen contents, $\alpha^{\prime}$ martensite formed as island type and became congregated with further strain. It can be clearly seen that the addition of nitrogen effectively suppress DIMT in metastable austenite steels, which is well matched with the kinetics results. Several previous works $[4,5,31]$ revealed the nucleation events of $\alpha^{\prime}$ martensite happened at the intersection of shear bands. The shear band is usual deformation structure in austenitic stainless steels, and the shear band intersections were known to play a role as nucleation sites of $\alpha^{\prime}$ martensite during DIMT $[4,13,17,18,26]$. In the austenite stainless steels, it has been reported that $\alpha^{\prime}$ martensite are formed via $\gamma \rightarrow \varepsilon \rightarrow \alpha^{\prime}$ transformation at shear band intersection $[2,5,26]$. The austenite is deformed thru planar shear bands which can be either $\varepsilon$ martensite, deformation twinning or planar slip band, depending on stacking fault energy. It is known that as the stacking fault energy increases, the deformation mechanism changes in the order of $\varepsilon$ martensite, deformation twinning, and planar slip [26]. According to the literature on DIMT of 304 stainless steels, $\alpha^{\prime}$ martensite can be formed at the intersection of the $\varepsilon$ martensite band or planar slip band [2,5,26]. In 301 austenitic stainless, a research reported that $\varepsilon$ martensite is not a necessary intermediate phase for $\alpha^{\prime}$ transformation, but rather $\alpha^{\prime}$ martenstie is directly transformed from $\gamma$ [1]. It has been reported that the addition of nitrogen in FCC-based iron-alloy slightly increases the stacking fault energy, but decreases rapidly after the addition is above that critical amount (0.2 0.3 wt. \%) [32]. In their research on Fe-18Cr-10Ni steel, when the amount of nitrogen is increased to more than $0.25 \mathrm{wt}$. \%, the stacking fault energy decreases sharply, which may change the deformation mechanism of austenite and the shear band may be thus composed of those of $\varepsilon$ martensite band or deformation twinning.

a)

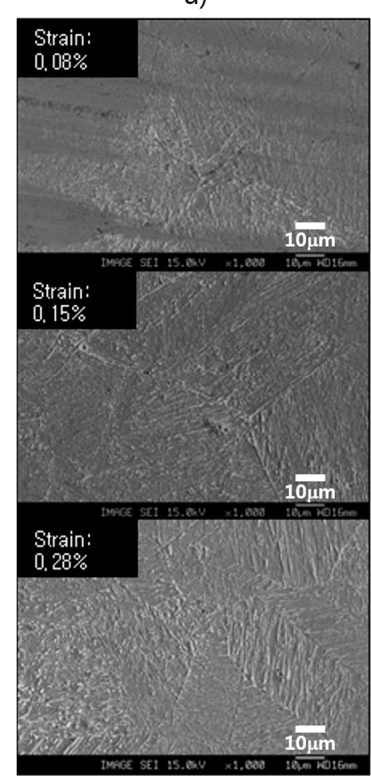

b)

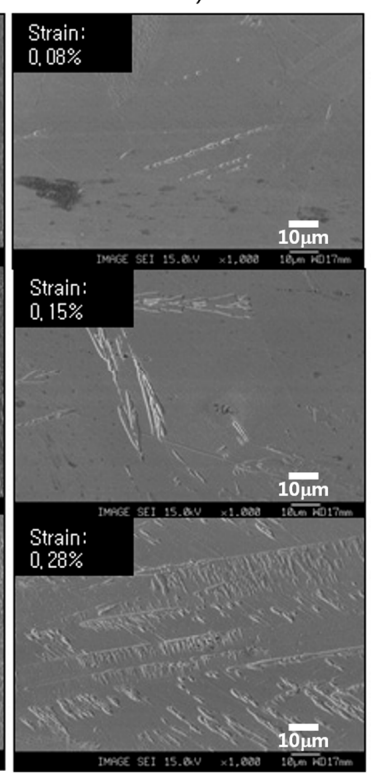

c)

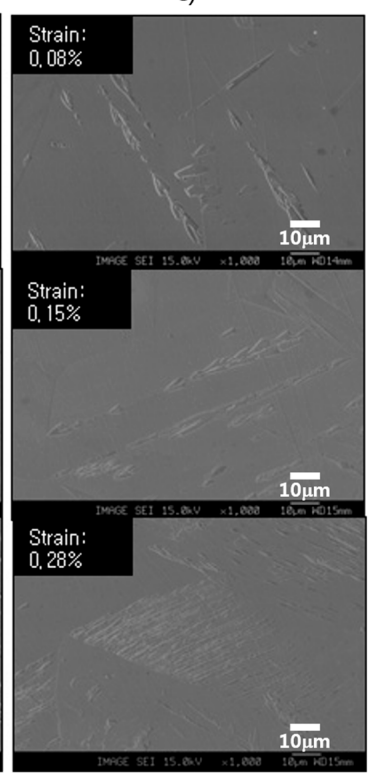

Figure 5. Scanning electron microscopy (SEM) iamges showing $\alpha^{\prime}$-martensite formation in specimen A (a), B (b), and C (c). 


\section{Conclusions}

In this investigation, the effect of nitrogen on DIMT was studied in terms of stress-strain response and transformation kinetics using recently proposed kinetics equation. The results are summarized as follows:

1. DIMT is viewed here as a simultaneous relaxation process of internal strain energy and the kinetics equation based on the inelastic deformation theory successfully described the variation of DIMT kinetics in metastable austenitic stainless steels.

2. In austenitic 301 stainless steels, addition of nitrogen in not observed to change the generation rate of nucleation site for DIMT ( $n$ is constant for 2.2) but effectively suppressed DIMT by stabilizing metastable austenite phase (decreasing $\beta$ and increasing $\varepsilon_{0}$ with increasing nitrogen contents).

3. The driving force deficiency for DIMT of nitrogen-added austenite is higher than that of nitrogen-free austenite and the difference results in the suppression of DIMT. More internal strain energy therefore is needed to transform nitrogen-added austenite into martensite than nitrogen-free austenite.

4. Stress-strain curve of nitrogen-free austenitic steel changed from sigmoidal to parabolic shape at transient strain. This transition disappeared with increasing nitrogen contents implying that DIMT is suppressed with added nitrogen.

Acknowledgments: This study has been conducted with the support of the Korea Institute of Industrial Technology as "Development of metal powder large-area DED process including pre-and post-processes based on simulations (KITECH EO-17-0041)".

Author Contributions: Jong Bae Jeon and Young Won Chang conceived and designed the experiments; Jong Bae Jeon performed the experiments; Jong Bae Jeon and Young Won Chang analyzed the data; Jong Bae Jeon and Young Won Chang wrote the paper.

Conflicts of Interest: The authors declare no conflict of interest.

\section{References}

1. Hedström, P.; Lienert, U.; Almer, J.; Odén, M. Stepwise transformation behavior of the strain-induced martensitic transformation in a metastable stainless steel. Scr. Mater. 2007, 56, 213-216. [CrossRef]

2. Olson, G.; Cohen, M. A Mechanism for the Strain-Induced Nucleation of Martensitic Transformation. J. Less Common Met. 1972, 28, 107-118. [CrossRef]

3. Shen, Y.F.; Li, X.X.; Sun, X.; Wang, Y.D.; Zuo, L. Twinning and martensite in a 304 austenitic stainless steel. Mater. Sci. Eng. A 2012, 552, 514-522. [CrossRef]

4. Lee, T.-H.; Oh, C.-S.; Kim, S.-J. Effects of nitrogen on deformation-induced martensitic transformation in metastable austenitic Fe-18Cr-10Mn-N steels. Scr. Mater. 2008, 58, 110-113. [CrossRef]

5. Gey, N.; Petit, B.; Humbert, M. Electron backscattered diffraction study of $\varepsilon / \alpha^{\prime}$ martensitic variants induced by plastic deformation in 304 stainless steel. Metall. Mater. Trans. A 2005, 36, 3291-3299. [CrossRef]

6. Guimaraes, J.R.C. The kinetics of deformation induced martensite. Scr. Metall. 1976, 10, 223-227. [CrossRef]

7. Iwamoto, T.; Tsuta, T.; Tomita, Y. Investigation on deformation mode dependence of strain-induced martensitic transformation in trip steels and modelling of transformation kinetics. Int. J. Mech. Sci. 1998, 40, 173-182. [CrossRef]

8. McReynolds, A.W. Effects of Stress and Deformation on the Martensite Transformation. J. Appl. Phys. 1949, 20, 896-907. [CrossRef]

9. Ahmedabadi, P.M.; Kain, V.; Agrawal, A. Modelling kinetics of strain-induced martensite transformation during plastic deformation of austenitic stainless steel. Mater. Des. 2016, 109, 466-475. [CrossRef]

10. Shin, H.C.; Ha, T.K.; Chang, Y.W. Kinetics of deformation induced martensitic transformation in a 304 stainless steel. Scr. Mater. 2001, 45, 823-829. [CrossRef]

11. Wang, Z.; Beese, A.M. Effect of chemistry on martensitic phase transformation kinetics and resulting properties of additively manufactured stainless steel. Acta Mater. 2017, 131, 410-422. [CrossRef] 
12. Wang, H.; Jeong, Y.; Clausen, B.; Liu, Y.; McCabe, R.J.; Barlat, F.; Tomé, C.N. Effect of martensitic phase transformation on the behavior of 304 austenitic stainless steel under tension. Mater. Sci. Eng. A 2016, 649, 174-183. [CrossRef]

13. Olson, G.B.; Cohen, M. Kinetics of strain-induced martensitic nucleation. Metall. Mater. Trans. A 1975, 6, 791-795. [CrossRef]

14. Weina, Z.; Zhenyu, L.; Zhibo, Z.; Guodong, W. The crystallographic mechanism for deformation induced martensitic transformation observed by high resolution transmission electron microscope. Mater. Lett. 2013, 91, 158-160. [CrossRef]

15. Ramirez, A.C.; Tsuta, T.; Mitani, T.; Osakada, K. Flow stress and phase transformation analyses in the austenitic stainless steel under cold working: Part 1, Phase Transformation Characteristics and Constitutive Formulation by Energetic Criterion. JSME Int. J. 1992, 35, 201-209. [CrossRef]

16. Isakov, M.; May, M.; Hiermaier, S.; Kuokkala, V.T. A model for the strain rate dependent plasticity of a metastable austenitic stainless steel. Mater. Des. 2016, 106, 258-272. [CrossRef]

17. Haidemenopoulos, G.N.; Aravas, N.; Bellas, I. Kinetics of strain-induced transformation of dispersed austenite in low-alloy TRIP steels. Mater. Sci. Eng. A 2014, 615, 416-423. [CrossRef]

18. Choi, H.C.; Ha, T.K.; Shin, H.C.; Chang, Y.W. The formation kinetics of deformation twin and deformation induced $\epsilon$-martensite in an austenitic Fe-C-Mn steel. Scr. Mater. 1999, 40, 1171-1177. [CrossRef]

19. Hedayati, A.; Najafizadeh, A.; Kermanpur, A.; Forouzan, F. The effect of cold rolling regime on microstructure and mechanical properties of AISI 304L stainless steel. J. Mater. Process. Technol. 2010, 210, 1017-1022. [CrossRef]

20. Roa, J.J.; Fargas, G.; Mateo, A.; Jiménez-Piqué, E. Dependence of nanoindentation hardness with crystallographic orientation of austenite grains in metastable stainless steels. Mater. Sci. Eng. A 2015, 645, 188-195. [CrossRef]

21. Hecker, S.S.; Stout, M.G.; Staudhammer, K.P.; Smith, J.L. Effects of Strain State and Strain Rate on Deformation-Induced Transformation in 304 Stainless Steel: Part I. Magnetic Measurements and Mechanical Behavior. Metall. Trans. A 1982, 13, 619-626. [CrossRef]

22. Reed, R.P. Nitrogen in austenitic stainless steels. JOM 1989, 41, 16-21. [CrossRef]

23. De Abreu, H.F.G.; de Carvalho, S.S.; de Lima Neto, P.; dos Santos, R.P.; Freire, V.N.; de Oliveira Silva, P.M.; Tavares, S.S.M. Deformation induced martensite in an AISI 301LN stainless steel: Characterization and influence on pitting corrosion resistance. Mater. Res. 2007, 10, 359-366. [CrossRef]

24. Beese, A.M.; Mohr, D. Identification of the Direction-Dependency of the Martensitic Transformation in Stainless Steel Using In Situ Magnetic Permeability Measurements. Exp. Mech. 2011, 51, 667-676. [CrossRef]

25. Ha, T.K.; Chang, Y.W. An internal variable theory of structural superplasticity. Acta Mater. 1998, 46, $2741-2749$. [CrossRef]

26. Humbert, M.; Petit, B.; Bolle, B.; Gey, N. Analysis of the $\gamma-\varepsilon-\alpha^{\prime}$ variant selection induced by $10 \%$ plastic deformation in 304 stainless steel at $-60^{\circ} \mathrm{C}$. Mater. Sci. Eng. A 2007, 454-455, 508-517. [CrossRef]

27. Weidner, A.; Segel, C.; Biermann, H. Magnitude of shear of deformation-induced $\alpha^{\prime}$-martensite in high-alloy metastable steel. Mater. Lett. 2015, 143, 155-158. [CrossRef]

28. Bhadeshia, H.K.D.H.; Honeycomb, R. Steels: Microstructure and Properties, 3rd ed.; Elsevier: London, UK, 2006; p. 118.

29. Sjoberg, J. Influence of Analysis on the Properties of Stainless Spring Steel. Wire 1973, 23, 155-158.

30. Huang, G.L.; Matlock, D.K.; Krauss, G. Martensite formation, strain rate sensitivity, and deformation behavior of type 304 stainless steel sheet. Metall. Trans. A 1989, 20, 1239-1246. [CrossRef]

31. Jeon, J.B.; Chang, Y.W. EBSD study on the evolution of microstructures during compressive deformation of an austenitic stainless steel. Int. J. Mod. Phys. B 2008, 22, 5971-5975. [CrossRef]

32. Yakubtsov, I.A.; Ariapour, A.; Perovic, D.D. Effect of nitrogen on stacking fault energy of f.c.c. iron-based alloys. Acta Mater. 1999, 47, 1271-1279. [CrossRef]

(C) 2017 by the authors. Licensee MDPI, Basel, Switzerland. This article is an open access article distributed under the terms and conditions of the Creative Commons Attribution (CC BY) license (http:/ / creativecommons.org/licenses/by/4.0/). 